\title{
laborhifórico
}

ISSN 2359-6910

https://revistas.ufrj.br/index.php/lh/

FONTES PRIMÁRIAS

Recebido em 24 de fevereiro de 2020

Aprovado em 30 de março de 2020

\section{Instruções de viagem a Europa ao primeiro pensionista da Academia Imperial de Belas Artes}

DOI: https://doi.org/10.24206/lh.v6i2.40556

Paola Matheus dos Santos

Graduanda em História da Arte pela Universidade Federal do Rio de Janeiro (UFRJ). Bolsista CNPQ de Iniciação Científica orientada pelo Prof. Dr. Alberto Martín Chillón.

E-mail: paolawms@gmail.com ORCID: https://orcid.org/0000-0002-5495-5975

Beatriz Dias Mikbail

Possui graduação em Letras Português-Espanhol pela Universidade Federal do Rio de Janeiro. Atualmente, faz mestrado em Letras Neolatinas, na área de estudos linguísticos (UFRJ). Participa do Laboratório de Estudos Filológicos (LabEFil), assim como da Revista LaborHistórico. Na graduação, atuou em pesquisas filológicas de documentos setecentistas da Família Real. No mestrado, pesquisa documentos da Coleção Pedro de Angelis, da Fundação Biblioteca Nacional. 


\section{RESUMO}

O objetivo deste trabalho é apresentar as Instruções de Viagem recebidas por Antônio Baptista da Rocha, aluno de arquitetura da Academia Imperial de Belas Artes, ganhador do primeiro Prêmio de Viagem à Itália em 1845.

Palavras-chave: Academia Imperial de Belas Artes. Prêmio de Viagem. Arquitetura. História da Arte. 


\section{Introdução}

No Arquivo Histórico da Escola de Belas Artes da Universidade Federal do Rio de Janeiro encontra-se um importante documento que apresenta as instruções de viagem à Europa destinadas ao primeiro pensionista de arquitetura da Academia Imperial de Belas Artes. Além de sua importância e também raridade, este documento expõe o funcionamento da Academia e o pensamento artístico dos que a conduziam e estipulavam suas matrizes de ensino.

Em 1816, seria criada por D. João VI a Escola Real de Ciências, Arte e Ofícios no Rio de Janeiro, que tinha por objetivo equiparar o ensino de ciências e artes no Brasil aos padrões europeus da eṕoca. Entretanto, foi aberta efetivamente somente em 1826, sob o nome Academia Imperial de Belas Artes e com o principal propósito de ser uma escola superior de arte.

Nesse período, a Academia era dividida em quatro seções: pintura histórica, arquitetura, escultura e paisagem. As seções, por sua vez, estavam divididas em cadeiras, e a seção de arquitetura possuía as cadeiras de desenho geométrico, arquitetura civil, desenho elementar e mecânica; estudos vistos pela Academia como essenciais para a formação do aluno de arquitetura.

Dentro do sistema de prêmios da Academia, no qual os melhores alunos eram recompensados, o mais importante e desejado era o Prêmio de Viagem a Itália, que foi realizado pela primeira vez em 23 de outubro de 1845. O Prêmio, nos moldes do Grand Prix de Rome, concedia ao aluno vencedor uma viagem à Itália, que tinha por objetivo o aprimoramento do aluno em contato com monumentos clássicos e grandes mestres europeus.

O primeiro aluno a receber o Prêmio de Viagem à Itália foi o aluno de arquitetura Antonio Baptista da Rocha. Durante os dois anos de seu pensionato, Antonio permaneceu na Europa realizando estudos de obras clássicas e em constante contato com importantes arquitetos, como o arqueólogo e arquiteto italiano Luigi Canina ${ }^{1}$. Em sua volta ao Brasil, Rocha se tornou secretário da Academia $^{2}$, foi professor substituto de arquitetura ${ }^{3}$ e trabalhou fazendo levantamento de obras públicas para o governo ${ }^{4}$.

No dia 21 de março de 1846, seriam entregues ao aluno Antônio Baptista da Rocha as instruções para sua estadia na Europa. Esse tipo de documento é muito importante para o estudo da história da

\footnotetext{
${ }^{1}$ Atas do diretor, Sessão Pública, Janeiro de 1849. Arquivo do Museu Dom João VI, EBA/UFRJ.

${ }^{2}$ Atas do diretor, 23 de outubro de 1850. Arquivo do Museu Dom João VI, EBA/UFRJ.

${ }^{3}$ Almanak administrativo, mercantil e industrial do Rio de Janeiro, 1851, edição 00008.

${ }^{4}$ Almanak administrativo, mercantil e industrial do Rio de Janeiro, 1850, edição 00007.
} 
arte no Brasil, pois nele estão não só as instruções para o aluno viajante - que por si só já são significantes - como também a visão do que era pedido no ensino da Academia e sua aplicação.

No documento é apresentada a importância da época da viagem, a qual deveria ser realizada em meados de março ou abril para que o aluno chegasse à Itália entre e junho ou julho. Este critério era requerido por motivos sanitários, pois o período de febres iniciava em Roma nessa época do ano e, desta forma, o estudante poderia afastar-se da capital e seguir seus estudos em vilas vizinhas seguramente e a tempo de enviar desenhos de fragmentos antigos ao Brasil para a exposição geral pública, que ocorreria no mês de Dezembro.

Mesmo a Academia Brasileira sendo pensada para ser um reflexo do que era o modelo de ensino francês, no Brasil o ensino artístico foi adaptado para as possibilidades e necessidades do país. É notável nas instruções que o aluno viajante deveria manter o foco firme na conviç̧ão de que a arquitetura era uma só, a clássica, a grega. Ou seja, fica claro que o aluno teria contato com todo tipo de arquitetura, mas que sempre deveria manter o foco na que era a real e verdadeira arquitetura e vista como a mais importante, devendo sempre se lembrar de mestres como Palladio. O documento apresenta a preocupação da Academia com outras arquiteturas, que são vistas como "meros ensaios primitivos do gênio humano" e "mais ou menos imprevisíveis".

Assim, o aluno deveria enviar no seu primeiro ano desenhos de fragmentos antigos e em seu segundo ano uma composição original claramente também nos princípios do clássico. Esses envios apresentariam a evolução do aluno e beneficiariam a Academia, pois serviriam de material de estudo para os alunos que permaneciam no Brasil e não poderiam estar em contato com as obras originais 5 .

As instruções para o aluno de arquitetura viajante na Europa podem ser encontradas no acervo digital do Arquivo Histórico da Escola de Belas Artes da UFRJ, que, através do processo de revitalização por meio do patrocínio da PETROBRAS, digitalizou o Arquivo catalogado da antiga Academia Imperial, e depois Escola Nacional de Belas Artes, que está sob sua guarda. O documento aqui transcrito encontra-se disponível em http://docvirt.com/MuseuDJoaoVI/, catalogado em Avulsos, de número 5704.

\footnotetext{
${ }^{5}$ PEREIRA, Sonia Gomes. A tradição artística e os envios dos pensionistas da Academia Imperial de Belas Artes do Rio de Janeiro. In: VALLE, Arthur; DAZZI, Camila. Oitocentos: Arte Brasileira do Império à República. Rio de Janeiro, Tomo 2, 2010.p. $617-638$.
} 


\section{Critérios de Transcrição}

A seguir são apresentadas as normas de transcrição e edição utilizadas. Pelo fato de o texto não apresentar grandes dificuldades a nível paleográfico, optamos por uma transcrição de natureza conservadora. Acreditamos que, embora não tenham sido feitas intervenções mais significativas, o texto editado estará acessível tanto a historiadores interessados na arte oitocentista, quanto ao público em geral.

1. A edição realizada foi de natureza conservadora.

2. Foram mantidas, tal como no modelo, a pontuação, a acentuação, assim como o uso de maiúsculas e minúsculas.

3. Foi respeitada a separação de linhas (edição justalinear) tal como no modelo, assim como os sinais utilizados para a translineação.

4. As abreviaturas não foram desenvolvidas, apresentando-se tal como estão no modelo.

5. Eventuais comentários feitos pelo editor aparecem como notas informativas, no rodapé da página.

6. Inserções do escriba ou do copista, para não conferir à mancha gráfica um aspecto demasiado denso, obedecem aos seguintes critérios: a) Se na entrelinha do documento original, entram na edição em alinhamento normal e entre os sinais: \langle\rangle ; $\langle\uparrow\rangle$, se na entrelinha superior; $\langle\downarrow\rangle$, se na entrelinha inferior.

7. Letra ou palavra(s) não legíveis por deterioração ou rasura justificam intervenção do editor com a indicação entre colchetes conforme o caso: [.] para letras, [ilegível] para vocábulos e [ilegível. + n linhas] para a extensão de trechos maiores. 


\section{Transcrição do texto}

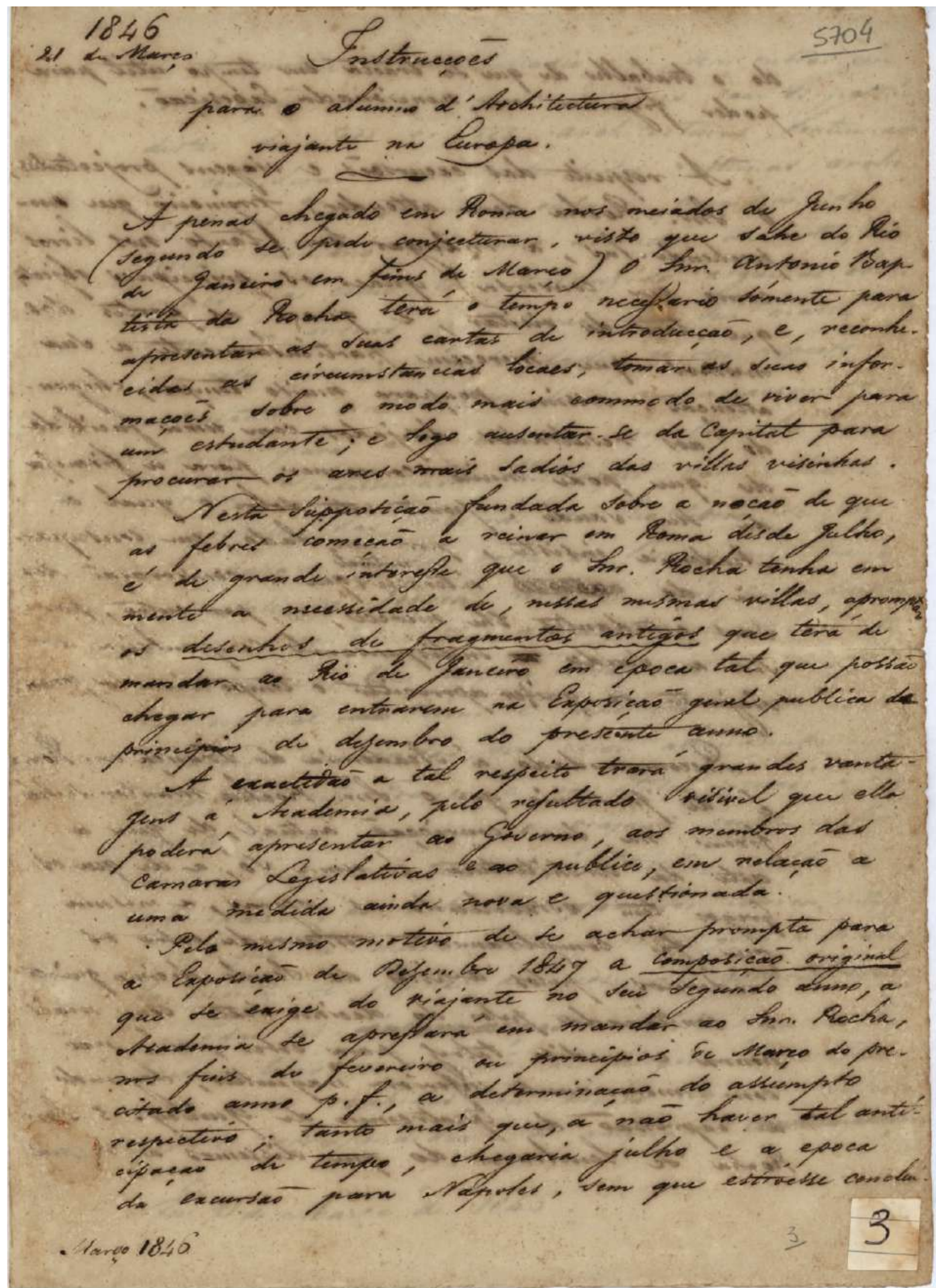


[fólio 1]

1846

21 de Março Instrucçoẽs

para o alumno d' Architectura

viajante na Europa.

A penas chegado em Roma nos meiados de Junho (segundo se pode conjecturar, visto que sahe do Rio de Janeiro em fins de Março) o Snr. Antonio Baptista da Rocha terá o tempo necessario sómente para apresentar as suas cartas de introducção, e, reconhecidas as circunstancias locaes, tomar as suas informaçoẽs sobre o modo mais commodo de viver para um estuante; e logo ausentar-se da Capital para procurar os ares mais sadios das villas visinhas.

Nesta supposiçaõ fundada sobre a noçaõ de que as febres começaõ a reinar em Roma desde Julho, é de grande interesse que o Snr. Rocha tenha em mente a necessidade de, nessas mesmas villas, apromptar os desenhos de fragmentos antigos ${ }^{6}$ que terá de mandar ao Rio de Janeiro em epoca tal que possaõ chegar para entrarem na Exposiçaõ geral publica de principios de dezembro do presente anno.

A exactidaõ a tal respeito trará grandes vantagens á Academia, pelo resultado visivel que ella poderá apresentar ao Governo, aos membros das Camaras Legislativas e ao publico, em relaçaõ a uma medida ainda nova e questionada.

Pelo mesmo motivo de se achar prompta para a Exposiçaõ de Dezembro 1847 a composiçaõ original ${ }^{7}$ que se exige do viajante no seu Segundo anno, a Academia se apressará em mandar ao Snr. Rocha, nos fins de fevereiro ou principios de Março do precitado anno p. f., a determinaçaõ do assumpto respectivo; tanto mais que, a naõ haver tal anticipaçaõ de tempo, chegaria julho e a epoca da excursão para Napoles, sem que estivesse conclui-

Março 1846

\footnotetext{
${ }^{6}$ O fragmento "desenhos de fragmentos antigos" está sublinhado.

${ }^{7} \mathrm{O}$ fragmento “composição original” está sublinhado.
} 


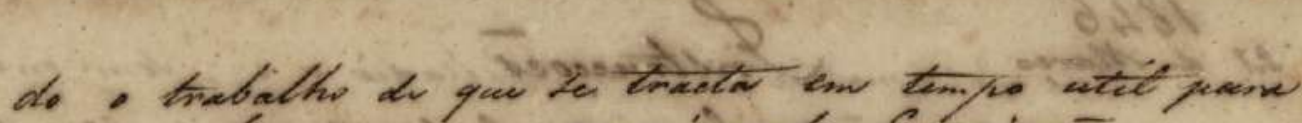

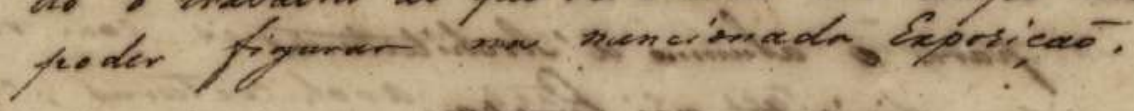

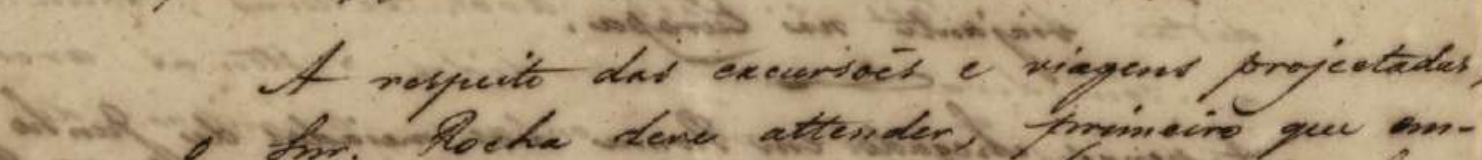

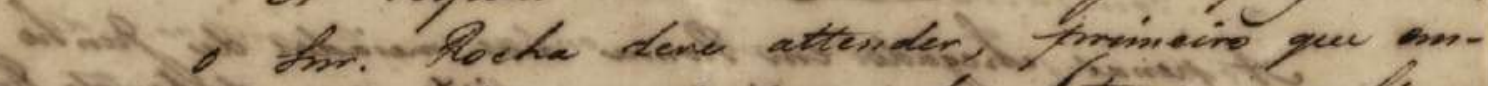

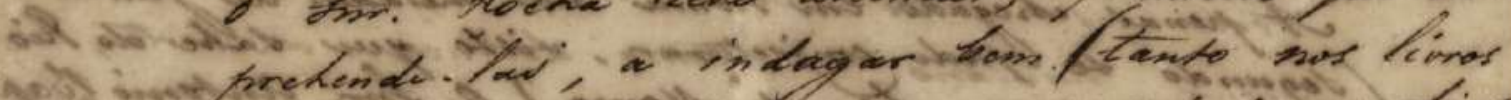

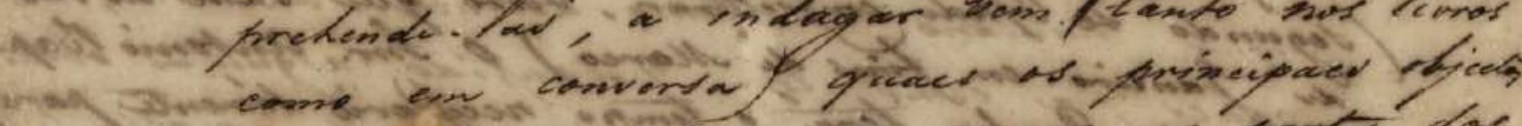

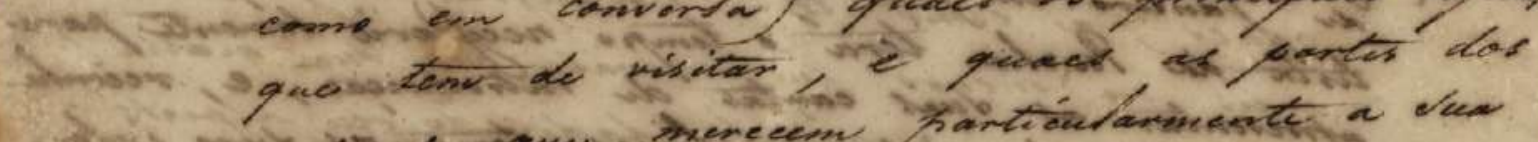

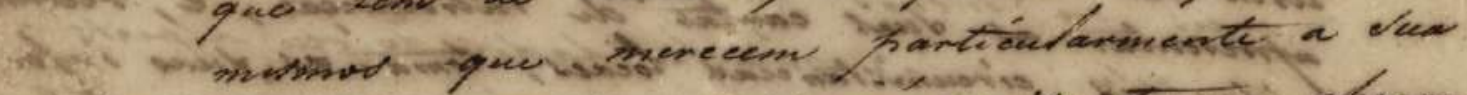

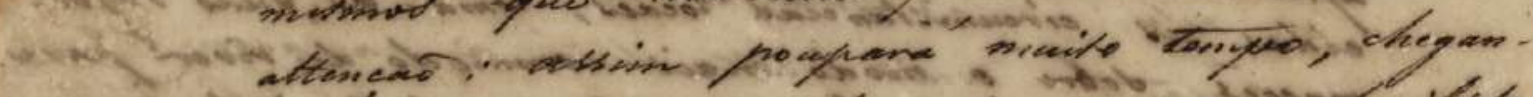

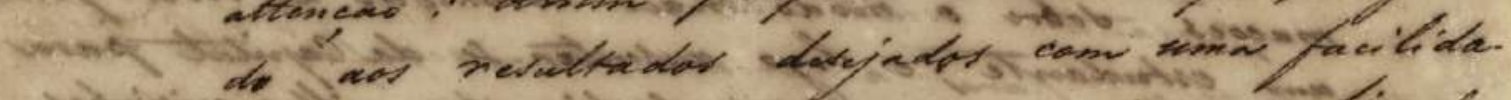

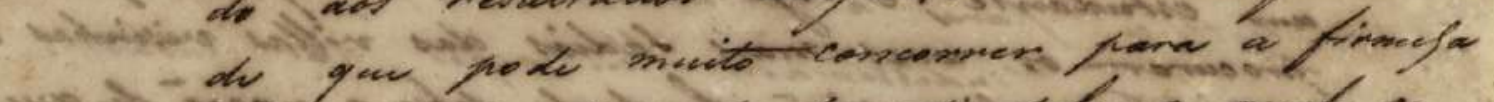

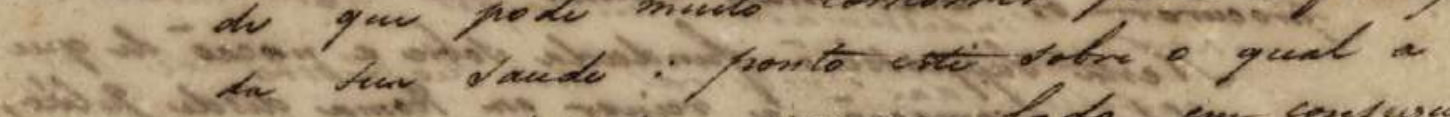

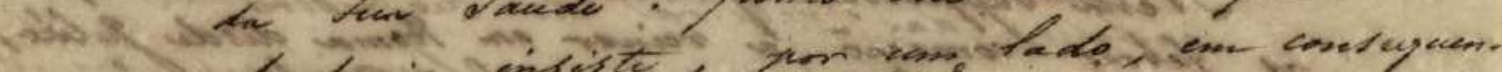

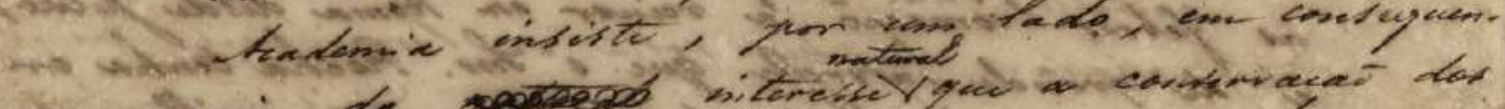

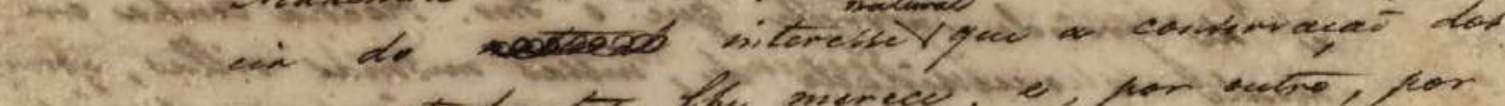

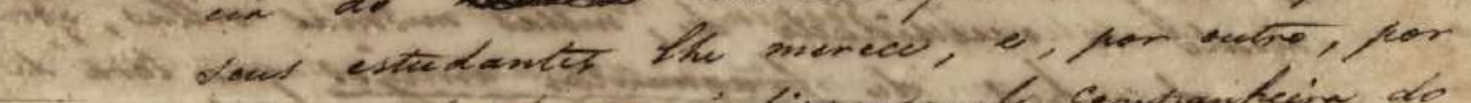

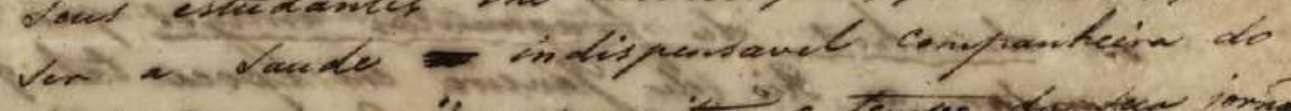

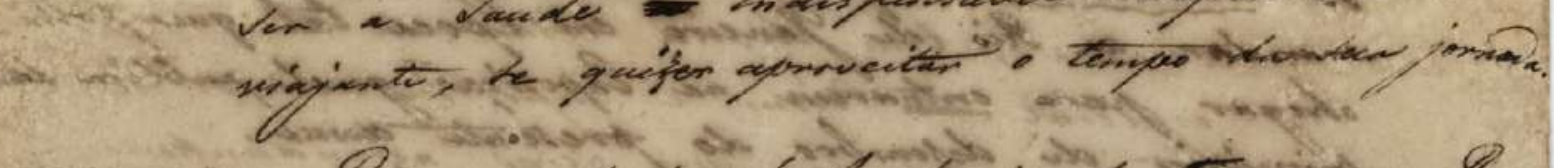

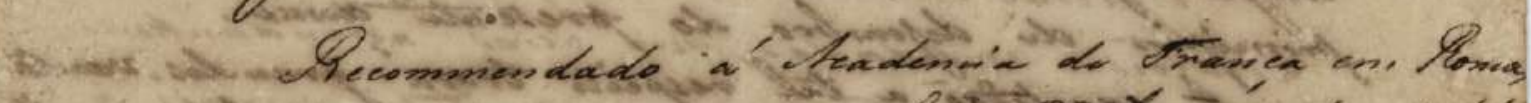

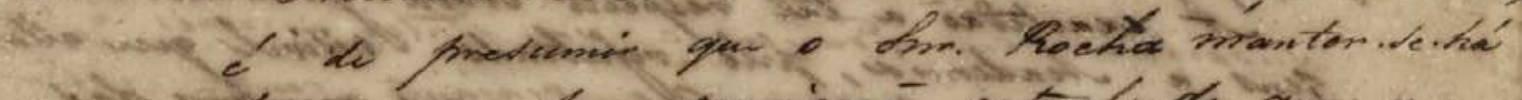

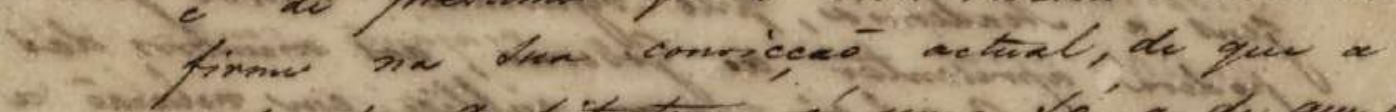

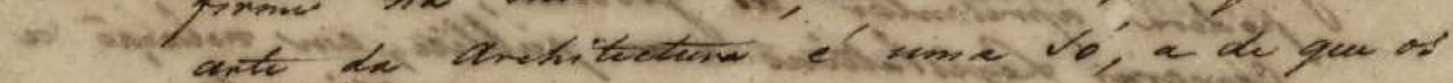

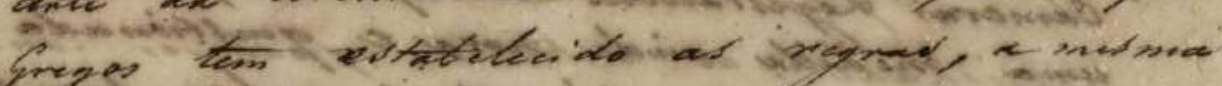

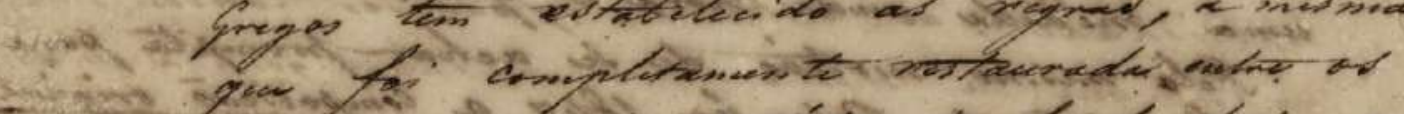

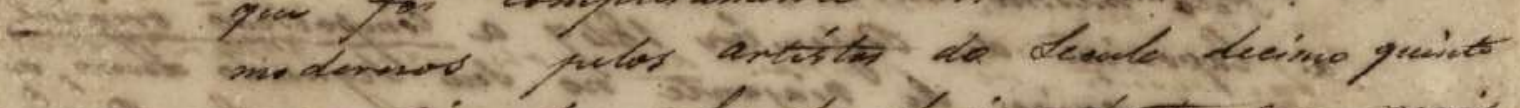

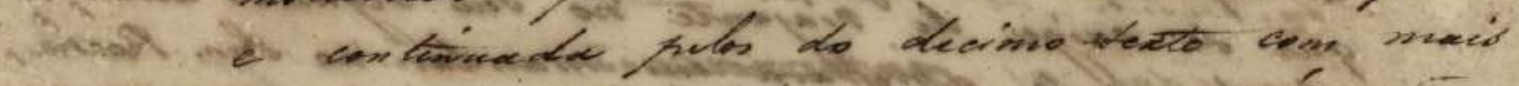

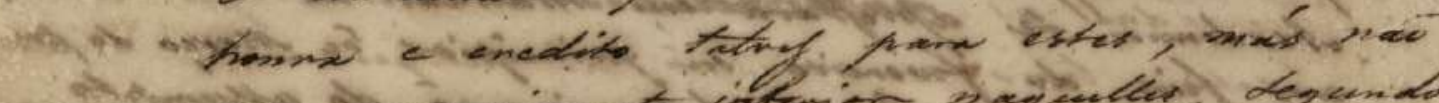

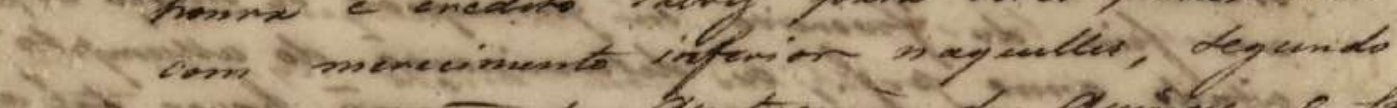

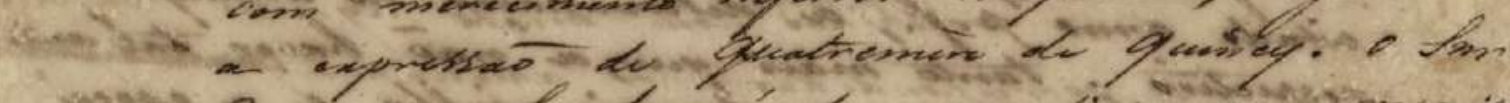

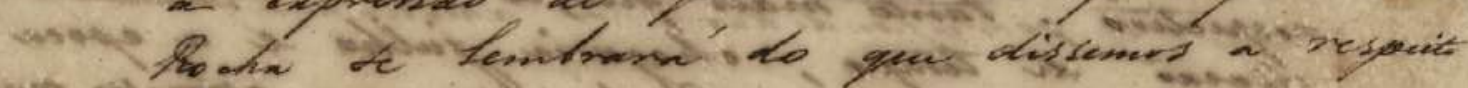

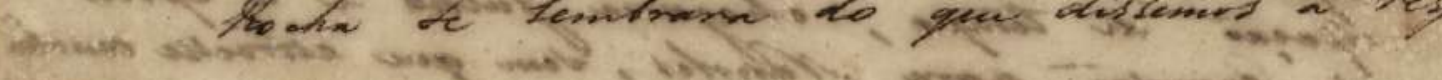

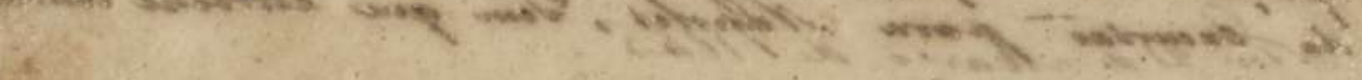
exist $=8$. 
[fólio 2]

do o trabalho de que se tracta em tempo util para poder figurar na mencionada Exposiçaõ.

A respeito das excursoẽs e viagens projectadas, o Snr. Rocha deve attender, primeiro que emprehende -las, a indagar bem (tanto nos livros como em conversa) quaes os principaes objectos que tem de visitar, e quaes as partes dos mesmos que merecem particularmente a sua attençaõ: assim poupará muito tempo, chegando aos resultados desejados com uma facilidade que pode muito concorrer para a firmesa da sua saude: ponto este sobre o qual a Academia insiste, por um lado, em consequencia do [ilegível] ${ }^{8}$ interesse $<\uparrow$ natural $>$ que a conservaçaõ dos seus estudantes the merece, e, por outro, por ser a saude [ilegível] $]^{9}$ indispensavel companheira do viajante, se quizer aproveitar o tempo da sua jornada.

Recommendado á Academia de França em Roma, é de presumir que o Snr. Rocha manter-se-há firme na sua convicçaõ actual, de que a arte da Architectura é uma só, a de que os Gregos tem estabelecido as regras, a mesma que foi completamente restaurada entre os modernos pelos artistas do Seculo decimo quinto e continuada pelos do decimo sexto com mais honra e credito talves para estes, más naõ com merecimento inferior naquelles, segundo a expressaõ de Quatremere de Quincy. o Snr Rocha se lembrará do que dissemos a respeito

\footnotetext{
${ }^{8}$ Há uma palavra rasurada, que não pôde ser decifrada.

${ }^{9}$ Há uma palavra rasurada, que não pôde ser decifrada.
} 
de dee nustro e de Palladio, $c$, Lem entran ene

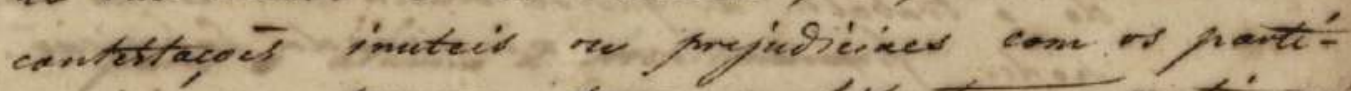

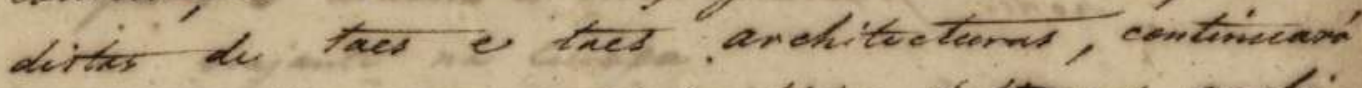

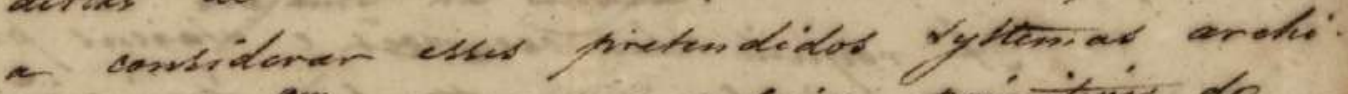
teetrusear como menes enbaies primiteves do

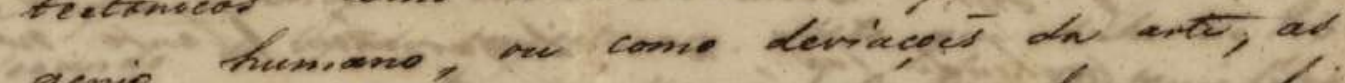

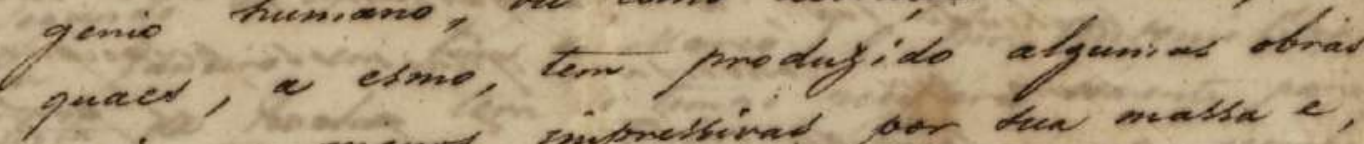

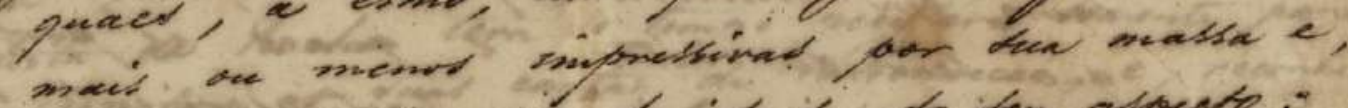

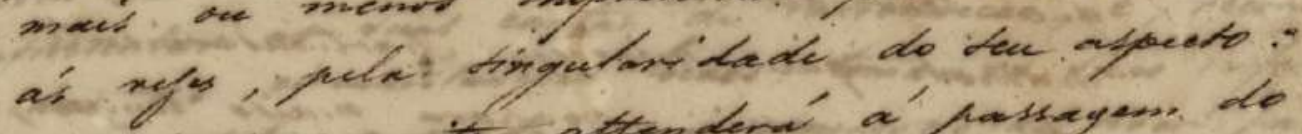

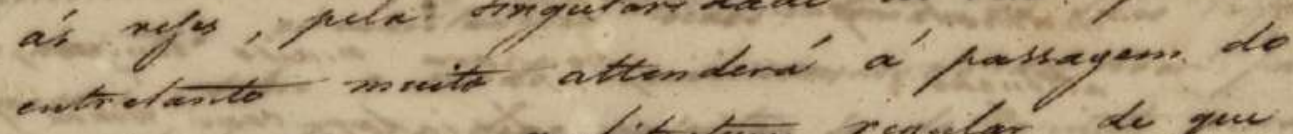

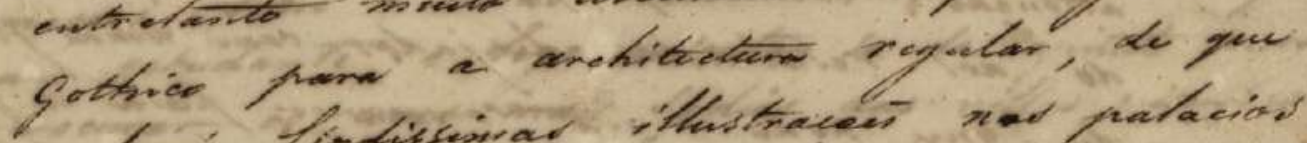
ahare limdiswivar ithstreceer nod patacios

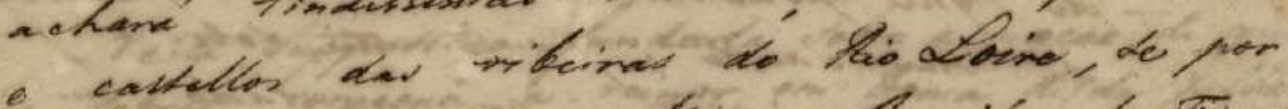

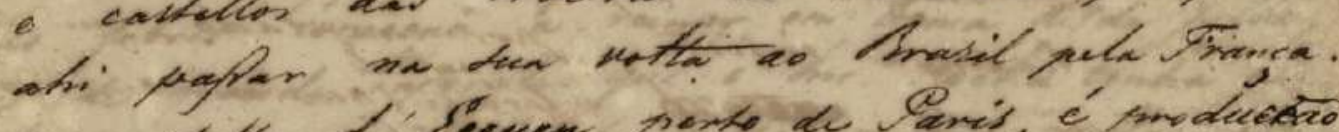

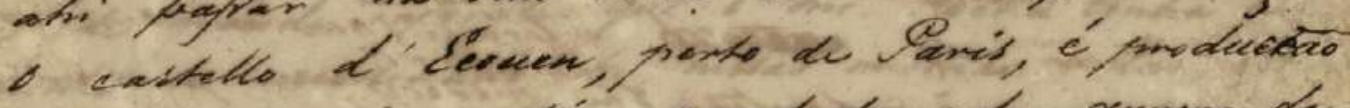
de rem quens mative, acondade pela arenon de.

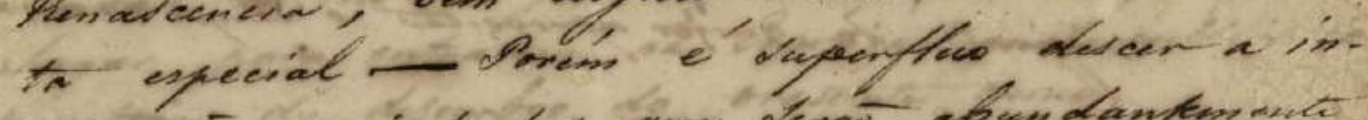

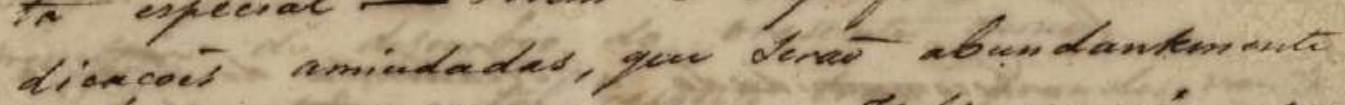

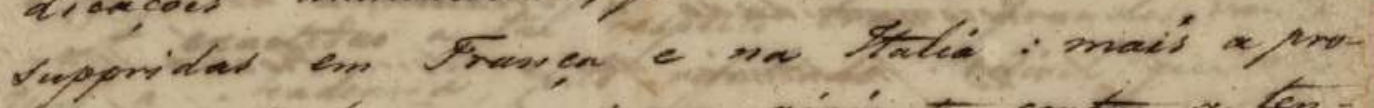

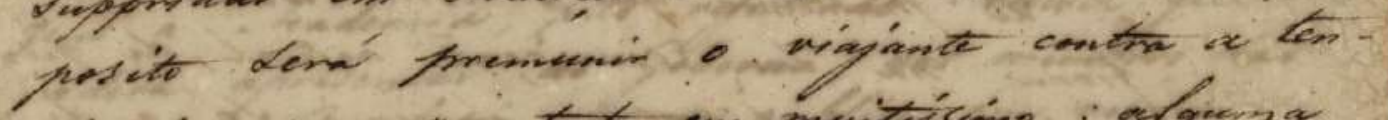

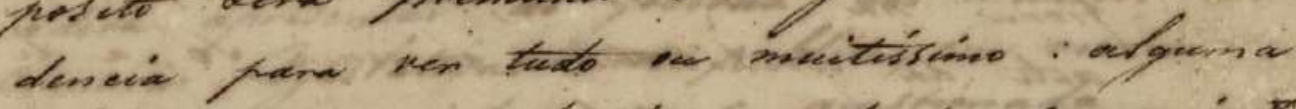

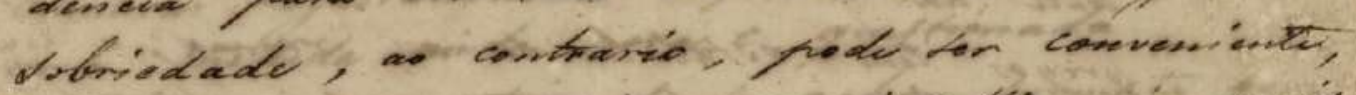

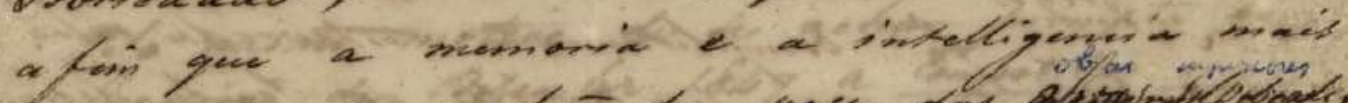

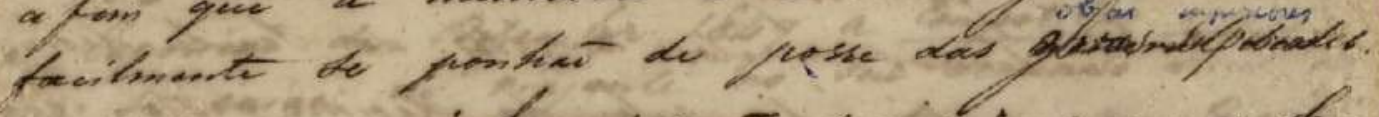

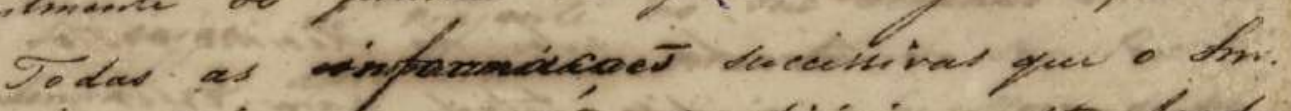

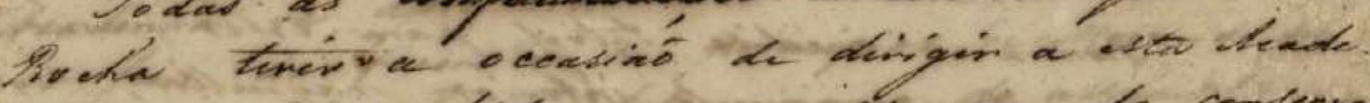

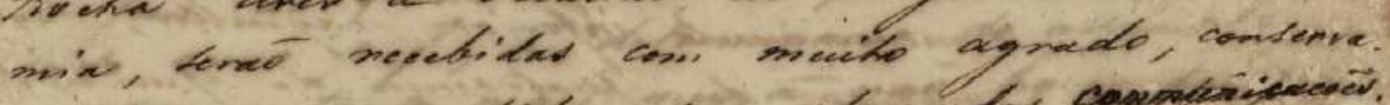

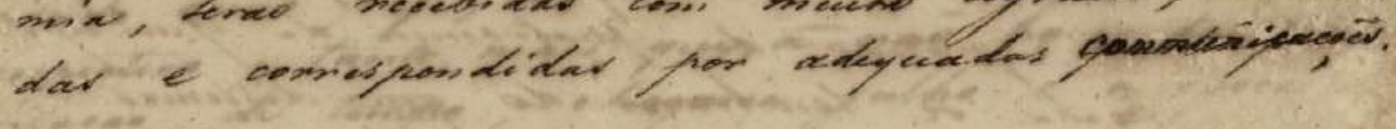
Im al de clbarco de $1846^{5}$ 
[fólio 3]

de seu mestre e de Palladio, e, sem entrar em contestaçoẽs inuteis ou prejudiciaes com os partidistas de taes e taes architecturas, continuará a considerar esses pretendidos systemas architectonicos $<\uparrow$ ou $>$ como meros ensaios primitivos do genio humano, ou como deviaçoẽs da arte, as quaes, a esmo, tem produzido algumas obras mais ou menos impressivas por sua massa e, ás veses, pela singularidade do seu aspecto: entretanto muito attenderá á passagem do Gothico para a architectura regular, de que achará lindissimas illustraçoẽs nos palacios e castellos das ribeiras do Rio Loire, se por ahi passar na sua volta ao Brasil pela França. O catello d' Ecouen, perto de Paris, é produccão de um genio nativo, acordado pela aurora da Renascencia, bem digna certamente de uma vista especial - Porém é superfluo descer a indicaçoẽs amiudadas, que seraõ abundantemente suppridas em França e na Italia: mais a proposito será premunir o viajante contra a tendencia para ver tudo ou muitíssimo: alguma sobriedade, ao contrario, pode ser conveniente, a fim que a memoria e a intelligencia mais facilmente se ponhaõ de posse das [ilegível] $<\uparrow$ obras superiores $>^{10}$.

Todas as informaçoẽs successivas que o Snr.

Rocha tiver a occasiaõ de dirigir a esta Academia, seraõ recebidas com muito agrado, conservadas e correspondidas por adequadas communicaçoẽs.

Em 21 de Março de 1846

${ }^{10}$ Acima da rasura do escriba, há uma anotação à caneta azul, feita provavelmente por outra mão: "obras superiores". 


\section{Referências bibliográficas}

CAVAlCANTI, A. M. T. Os Prêmios de Viagem da Academia em Pintura. In: PEREIRA, Sonia Gomes (Org.). 185 anos da Escola de Belas Artes. Rio de Janeiro: UFRJ, 2001/2002, p. 69-92.

FERNANDES, C. V. N. Os caminhos da arte. O ensino artístico na Academia Imperial das Belas Artes - 1850/1890. Tese de Doutorado - IFCS/UFRJ, Rio de Janeiro, 2001.

PEREIRA, S. G. Arte, ensino e academia: estudos e ensaios sobre a Academia de Belas Artes do Rio de Janeiro. Rio de Janeiro: Mauad Faperj, 2016.

PEREIRA, S. G. A tradição artística e os envios dos pensionistas da Academia Imperial de Belas Artes do Rio de Janeiro. In: VALLE, Arthur; DAZZI, Camila. Oitocentos: Arte Brasileira do Império à República. Rio de Janeiro, Tomo 2, 2010. p. 617 - 638.

ROCHA-PEIXOTO, G. Arquitetos do Brasil imperial: a obra arquitetônica dos primeiros alunos da Academia Imperial de Belas Artes. Tese de Doutorado - IFCS/UFRJ, Rio de Janeiro, 2004. 